\title{
Speciation in a Late Cretaceous lineage of Veenia (Ostracoda)
}

\author{
R. A. REYMENT \\ Paleontologiska Institutionen, Uppsala Universitet, Box 558 S75122 Uppsala, Sweden
}

\begin{abstract}
Special environmental conditions developed in the Tarfayan Basin of southwestern Morocco during the Cenomanian to Coniacian, presumably in response to eustatic changes of sea-level. The passage of $V$. rotunda to $V$. rahhalii took place over approximately $2 \times 10^{5}$ years, the appearance of the new species being heralded by the development of a new morph displaying some of the properties of the descendant species. This morph coexisted with the normal morph of $V$. rotunda. Using methods of quantitative genetics it is shown that speciation could have occurred either by weak selection or by random genetic drift in a deme of moderate size. The phenotype is regionally stable, hence the observed morphological changes in the lineage are of genetic origin. The morphological trend is regional.
\end{abstract}

\section{INTRODUCTION}

During Cenomanian to Coniacian time, rather special conditions of sedimentation were developed in the Tarfayan coastal sedimentary basin of southwestern Morocco. A series of marls and limestones, rich in organic matter, was deposited and what can in part be described as endemic conditions existed for many groups of organisms inhabiting this environment. Various interpretations have been advanced for explaining the nature of the Tarfayan sedimentary environment, all of which are based on the concept of changing palaeobiogeographical relationships arising from the lateral movements of the continents bordering the Atlantic during the Late Cretaceous.

More directly, attempts have been made to explain the faunal composition of the Cenomanian through Coniacian by recourse to hypotheses calling upon the effects of upwelling, trade winds and the influx of cold Arctic waters (Wiedmann et al., 1978), although the factual bases for these are far from unchallengeable. Bathyal reconstructions cannot be made independently of considerations of the nekroplanktic dispersal of abundantly occurring ammonite shells; thus conclusions based on the break-out of Arctic waters must rhyme with the evidence for the opening of the northern reaches of the Atlantic.

The nature of the ostracod faunas of the Tarfayan Upper Cretaceous differs markedly from that of the molluscan associations in that they are composed of very few species and, for the most part, relatively few individuals. The lime-rich environment of the Tarfayan sedimentary basin seems to have been rather hostile to ostracods.

In the present paper, a lineage consisting of Veenia rotunda Reyment and Veenia rahhalii Reyment is analyzed by means of methods of quantitative genetics, adapted for palaeontological situations by Lande (1976, 1979a, 1979b). An important feature of the speciation event is provided by the development of what seems to be an ecologically cued polymorph (cf. Clark, 1976) towards the top of the range of $V$. rotunda.

\section{MATERIAL}

The material described here is derived from two boreholes, the official Moroccan designations of which are S09 and S21. These were drilled in the coastal area of the Tarfayan Basin for the Service Géologique du Maroc by the Bureau de Recherches Minières, Rabat in 1975 in connection with a programme of hydrocarbon exploration.

The Cenomanian to Coniacian sequence lacks significant stratigraphical breaks, according to Wiedmann et al. (1978) and the environment of deposition is largely homogeneous. The specimens studied here come from a part of the succession marked by the effects of an increasing water-depth, resulting from the Cenomano-Turonian eustatic transgression.

The characters measured on the specimens are (1) length of carapace, (2) height of carapace, (3) length of the posterodorsal margin, and (4) the distance between the eye-tubercle and the posteroventral corner of the carapace.

\section{ORNAMENTAL MORPHS}

The normal ornamental development of $V$. rotunda consists of two anterior rows of reticulations and a lateral pattern of fine pits and, or, vague reticulations. 
This ornamental pattern persisted over most of the range of the species with but slight variations (Reyment, 1978). At the top of the range of the species, the normal morph occurs together with a strongly reticulated variant (Pl. 1). The ratio between the morphs in the youngest sample of $V$. rotunda is $1: 10$, in favour of the reticulated morph. This type of variation has been given close attention by Clark (1976) who has studied its occurrence among living invertebrates and to which he has applied the term "environmentally cued polymorphism". Under certain sustained ecological conditions the new morph can oust the "normal variant" and eventually give rise to a new species through the extinction of the original morph. A mechanism of this kind would provide a possible explanation for the speciation event described here.

The descendant species, $V$. rahhalii, is like the strongly ornamented morph of $V$. rotunda, but it is more rounded and trianguloid, the outer row of anterior reticulations is subdivided, and there are one or more smooth posterolateral zones. It is also significantly smaller than the ancestral form. The two species have not been found together.

\section{ANALYSIS OF PHENOTYPIC EVOLUTION}

The basic study for analyzing phenotypic evolution in fossil lineages by quantitative genetics is that of Lande (1976). In that paper, a method was developed for determining the minimum selective mortality necessary to produce an observed rate of evolution. An alternative test for the hypothesis of evolution by random genetic drift in relation to the effective population size was also given.

How can we determine the minimum amount of selection, or the proportion of the population that must be culled each generation, to yield a given rate of evolution (the terminology comes from the genetics of animal husbandry)? This form of selection is known as truncation selection (cf. Bulmer, 1980; Hartl, 1980; Falconer, 1960; Lande, 1976).

The realized heritability of a character $h^{2}$ is of importance here: this quantity is determined by the genetic system, the breeding structure of the population and the environment and may change during the course of evolution. It is, moreover, influenced by the effective population size (Hartl, 1980; Lande, 1976). The heritability of most morphological characters in large, stable populations lies between 0.1 and 0.6 (Falconer, 1960; Hallauer \& Miranda, 1981; Lande, 1980b; Strickberger, 1976). The phenotypic variance $\sigma^{2}$ and t, the number of generations (estimated from the absolute time occupied by the lineage and the demographic generation time of the population) are required, as are also the phenotypic change, $\mathrm{z}$, and $\mathrm{N}$ the population size. If $\mathrm{h}^{2}$ and $\sigma^{2}$ are approximately constant, the total morphological change after $t$ generations is:

$$
|z| / \sigma=\frac{h^{2} \mathrm{te}^{-b^{2} / 2}}{\sqrt{2 \pi}}
$$

where $b$, the number of phenotypic standard deviations between the average phenotype and the truncation point (all phenotypes lying below this point have a fitness of one, whereas those located above it have a fitness of zero) is yielded by the relationship:

$$
b= \pm \sqrt{-2 \log _{\mathrm{e}}\left(\frac{}{} \frac{2 \pi|\mathrm{z}| / \sigma)}{\mathrm{h}^{2} \mathrm{t}}\right.}
$$

The proportion of individuals culled each generation is obtained by entering the value of $b$ computed from equation (2) into a table of the standard normal distribution.

The second evolutionary mechanism to be considered is that of random genetic drift. Wright $(1931,1932)$ developed a theory of evolution based on the interaction of natural selection, migration, and random genetic drift in genetic systems. Random genetic drift is thought to be an important factor in the crossing of thresholds between adaptive zones for phenotypic characters on a sort of lottery ticket basis.

Fossil data cannot give a valid proof of random genetic drift having occurred, as any pattern of morphological change could have been caused by migrational episodes or fluctuating selection. All that can be deduced is whether random genetic drift is potentially important in a particular case of phenotypic evolution. One wishes to determine how small the effective population size must be for there to be a significant chance of the observed morphological changes having been caused by random genetic drift.

The limiting case of no selection gives the maximum rate of evolution which can be developed by random genetic drift. After $\mathbf{t}$ generations, in the absence of selection, the probability distribution of the average phenotype is normal with expected value zero at the starting point and variance $h^{2} \boldsymbol{\sigma}^{2} \mathrm{t} / \mathrm{N}$. The effective population size at which there is a $5 \%$ chance of randomly drifting a distance at least $z$ in either direction in $t$ generations, $N_{e}$, is obtained when the observed magnitude of morphological change $|z|=1.96\left(h^{2} \sigma^{2} t / N\right)^{\frac{1}{2}}$. The value of $\mathrm{N}_{\mathrm{e}}$ is obtained from the relationship:

$$
\mathrm{N}_{\mathrm{c}}=\frac{(1.96)^{2} \mathrm{~h}^{2} \mathrm{t}}{(\mathrm{z} / \sigma)^{2}}
$$

If $\mathbf{N}>\mathrm{N}_{\mathrm{c}}$, the hypothesis of selective neutrality can be rejected at the $95 \%$ level of confidence.

The above results of Lande (1976) can be applied to the Veenia lineage. The data consist of four samples from borehole S21, including the descendant species, 


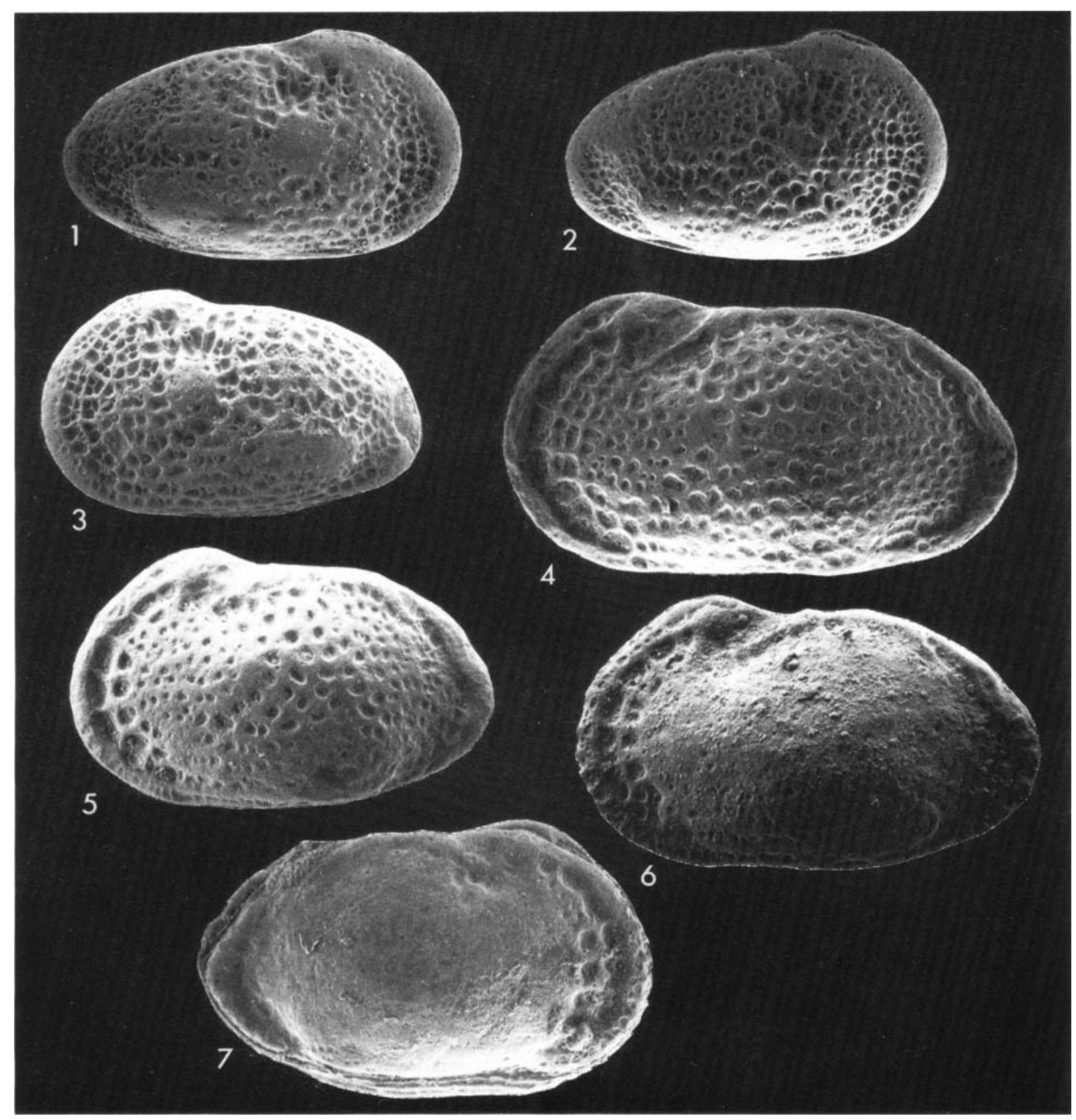

Explanation of Plate 1

All specimens are approximately $\mathrm{x} 45$

Figs. 1-3. Veenia rahhalii Reyment. Three specimens from depth $175 \mathrm{~m}$, borehole S21, southwestern Morocco. Note the tendency to develop smooth fields in the posterior half of the carapace and the subdivision of the anteromarginal rows of reticulations.

Figs. 4, 5. Veenia rotunda Reyment. Two examples of the reticulated morph from depth $194 \mathrm{~m}$, borehole $\mathrm{S} 21$. The inner anteromarginal row of reticulations is subdivided in fig. 4 only.

Fig. 6. Veenia rotunda Reyment. Example of the "normal" morph from depth $194 \mathrm{~m}$, borehole $\mathrm{S} 21$. Compare the ventrolateral bulge of this specimen with that of fig. 3 .

Fig. 7. Veenia rotunda Reyment. Example of the "normal" morph from depth $141 \mathrm{~m}$, borehole S09, the top of the range of the species in that borehole. 
and five samples of $V$. rotunda from borehole S09. Firstly, we need some idea of what $N$, the average actual size, might have been. An absolute upper level for the deme-size attainable by marine ostracods would appear to be $4 \times 10^{5}$ individuals per $\mathrm{m}^{2}$ (Theisen, 1966). In the vast majority of cases, however, deme-sizes are probably very much less (Uffenorde, 1972), of the order of a few tens of thousands. For estimating $t$, the number of generations, we use the fact that marine ostracods have one or two generations per year (Theisen, 1966, Uffenorde, 1972); to be conservative, we shall assume that the species considered here had one generation a year.

Ostracods seldom display a normal Mendelian sexual ratio, the most commonly occurring proportion among marine ostracods being one male to three females. In the present material, the ratio is about one male to ten females. Uneven sexual proportions would reduce the effective population size below what is indicated by equation (3), as is indicated by the relationship $N=4 N_{M} N_{F} /\left(N_{M}+N_{F}\right)$, where $N_{M}$ denotes the number of sexually mature males and $N_{F}$ the number of sexually mature females. The greater the size of the deme, however, the less serious will be the effects of unequal sexual proportions (Hartl, 1980, p. 160-161).

How is the heritability to be assessed? This ratio of the additive genetic variance to the phenotypic variance can only be computed directly for living organisms and no work has been carried out on living crustaceans. However, if equations (2) and (3) are worked out for a range of heritabilities ( $h^{2}$ ranges from 0 to 1$)$, empirical confidence intervals can be constructed for a species without our needing to know the value of the heritability for any particular species and system (usually morphological) involved. This approach has the added advantage that variability in $\mathbf{h}^{2}$ through time is accommodated within the range of values computed. The problems attaching to the statistical deficiences of $h^{2}$ are discussed by Bulmer (1980), Hartl (1980) and Kempthorne (1957). The method of empirical confidence intervals is more useful for estimations of selective mortality as the curve for b rises slowly over a wide range of values of $\mathbf{h}^{2}$.

The results of the calculations for the sequence of $V$. rotunda (borehole $\mathrm{S} 09$ ) and $V$. rotunda $-V$. rahhalii (borehole S21), based on the height of the carapace, are listed in Table 1. Height was the preferred variable here as it was found to be less influenced by extraneous sources of variation. The discriminant function scores for all variables were used for obtaining a multivariate expression of the transition from $V$. rotunda to $V$. rahhalii.

The sequence for $V$. rotunda (borehole S09) gives evidence of rather weak selection for height of the order of 5-10 selective deaths per million per generation (but which Lande (1980a) considers to be sufficient for speciation to occur). Under the hypothesis of selective neutrality, the effective deme-size needed for there to be a $5 \%$ chance of drifting a distance of $0.013 \mathrm{~mm}$ is between 13000 and 28000 individuals. This is certainly large but it is well within the realm of possibility for ostracods, taking into account that this figure encompasses the uneven sexual ratio and all larval stages of the material. The number of adults in the deme would lie between 1300 and 3000 and with the $1: 10$ sexual ratio taken into account, the effective population size reduces to 500-1000 individuals.

Consider now the transition from $V$. rotunda to $V$. rahhalii. The result for the hypothesis of evolution by selection leads to the same result as in the foregoing case ( $c f$. Table 1 ), namely from 6 to 13 selective deaths per million individuals per generation. The effective deme-size for drifting a distance of $0.085 \mathrm{~mm}$ is from 10000 to 19000 individuals, with again the provisor that this represents the entire population, including immature individuals. This lies well within the bounds of possibility for producing evolutionary changes on the scale recorded in the present material by random genetic drift, as the effective deme-size for sexually mature individuals would have been between 500 and 1000 .

The level-by-level comparison of evolution in $V$. rotunda yields very large values of $\mathrm{N}_{\mathrm{e}}$, all of which are greatly in excess of $20 \times 10^{7}$ individuals and consequently far greater than any known deme-size for ostracods. It is, therefore, not likely that random drift could have been significant in the earlier evolutionary history of the species. The observed morphological changes for the main part of the range of $V$. rotunda are probably the outcome of a developmental response to a slowly changing environment (Emlen, 1973). Using the discriminant function scores for the transition from $V$. rotunda to $V$. rahhalii, we obtain virtually the same result as was found for height, which is almost certainly a reflection of the relatively high degree of integration in the dimensions of the ostracod carapace (cf. Lande, 1976).

The passage from ancestor to descendant has $h^{2} t \approx$ 10000, which when referred to Fig. 2 of Lande (1976, p. 325) indicates that even fairly weak stabilizing selection would prevent a population of the size involved (500-1000 individuals) from moving more than two phenotypic standard deviations from the optimum. For there to be a reasonably certain chance for a deme to evolve in this manner, it would have to be composed of about 100 effective individuals at the most. It is, nonetheless, possible for some populations to succeed in crossing an adaptive threshold by chance (Lande, 1976). 
Table 1. Minimum amounts of selection (proportion culled per generation) necessary to explain the transitions of Fig. 1 and effective population sizes for rejection of the neutral hypothesis at the $95 \%$ confidence level.

\begin{tabular}{lllll}
\hline Transition & $\mathrm{h}^{2}$ & $\mathrm{~N}_{\mathrm{e}}$ & Number culled & $\mathrm{t}$ \\
\hline $\begin{array}{l}\text { S09, oldest to S09 } \\
\text { youngest }(V . \text { rotunda) }\end{array}$ & $0.3-0.6$ & $13000-28000$ & $5-10 \times 10^{6}$ & 200000 \\
$\begin{array}{l}\text { S21, youngest } V . \text { rotunda } \\
\text { to } V \text {. rahhalii }\end{array}$ & $0.3-0.6$ & $10000-19000$ & $6-13 \times 10^{6}$ & 180000 \\
$\begin{array}{l}\text { S21, youngest } V . \text { rotunda } \\
\text { to } V \text {. rahhalii; } \\
\text { discriminant scores }\end{array}$ & $0.3-0.6$ & $10000-20000$ & $6-13 \times 10^{6}$ & 180000 \\
\hline
\end{tabular}

\section{MULTIVARIATE ANALYSIS OF THE SEQUENCES}

The multivariate statistical method of canonical variate analysis was applied to the four variables in order to produce means suitable for examining morphological changes through time. In connection herewith it was found necessary to stabilize the canonical variate coefficients by shrinkage (Campbell \& Reyment, 1978).

Firstly, for the sequence of $V$. rotunda in borehole S09 the following linear combinations correspond to the first two canonical roots:

$$
y_{1}=-0.13 x_{1}+1.36 x_{2}+0.15 x_{3}-0.56 x_{4}
$$

(first canonical vector)

and

$$
\begin{aligned}
y_{2}=-0.17 x_{1}+0.40 x_{2}-1.13 x_{3}+0.13 x_{4} \\
\text { (second canonical vector). }
\end{aligned}
$$

The transitional sequence of borehole $\mathrm{S} 21(\mathrm{~V}$. rotunda to $V$. rahhalii) yields the following pair of linear combinations:

$$
\mathrm{y}_{1}=-0.15 \mathrm{x}_{1}+0.92 \mathrm{x}_{2}-0.98 \mathrm{x}_{3}+0.07 \mathrm{x}_{4}
$$

(first canonical vector)

and

$$
\begin{array}{r}
y_{1}=0.15 x_{1}+0.73 x_{2}+0.45 x_{3}-0.29 x_{4} \\
\text { (second canonical vector). }
\end{array}
$$

We note that $x_{2}$ (height) behaves analogously in both sets of equations and that the contribution from $\mathrm{x}_{1}$ (length) is small in all combinations. This is a reflection of the relative stability of height of carapace in space and time; this is further demonstrated by the principal component analyses summarized in Table 2 . Variables 3 and 4 show no consistent pattern in the canonical vectors owing to the change in shape during the species transition.

The plot of the first canonical variate means for both sequences is shown in Fig. 1. It will be seen that there is trend in both sequences but that it is not monotonic, there being first an increase in size and then a regular diminution in size.

Significant morphological trend in a sequence of observations is often taken as evidence of natural selection. However, random genetic drift, without selection, will sometimes produce a trending evolutionary curve ( $c f$. Raup (1977) who seems to have exaggerated the biological extrapolarity of monotonic trend in computer-simulated evolutionary sequences). In the case of the present material, the trend in both sequences suggests that the changes leading to the speciation event, recorded only at site S21, might be of a regional nature. It is not possible to place too much confidence in this observation as both series are short. Nonetheless, they are correlated and in view of the fact that the phenotypes at both localities are stable (see below) and equivalent, the trending effect would seem to be genuine, hence of genetic origin.

\section{REGIONAL STABILITY OF THE PHENOTYPE}

The regional stability of the phenotype was tested by a suite of component analyses (these gave stable results without the need for any iterative stabilization technique such as is often necessary for palaeontological data) and by the method of Lande (1979a). The essential results are summarized in Tables 2 and 3.

The principal component analyses show remarkable stability in both time and space, indicating that the observed morphological changes are regionally valid and must be of genetic origin. The first principal components for all samples are virtually identical. The second shows slight (though unimportant) variations in the first and second elements, whereas the third and fourth elements are identical throughout the entire suite of samples. There is close agreement in the third component, apart from slight instability in variables with very small loadings. The fourth principal components are also close. Such a degree of concordance is rare in principal component analyses of morphological data and can only serve to support the hypothesis of regional stability in the phenotype. 


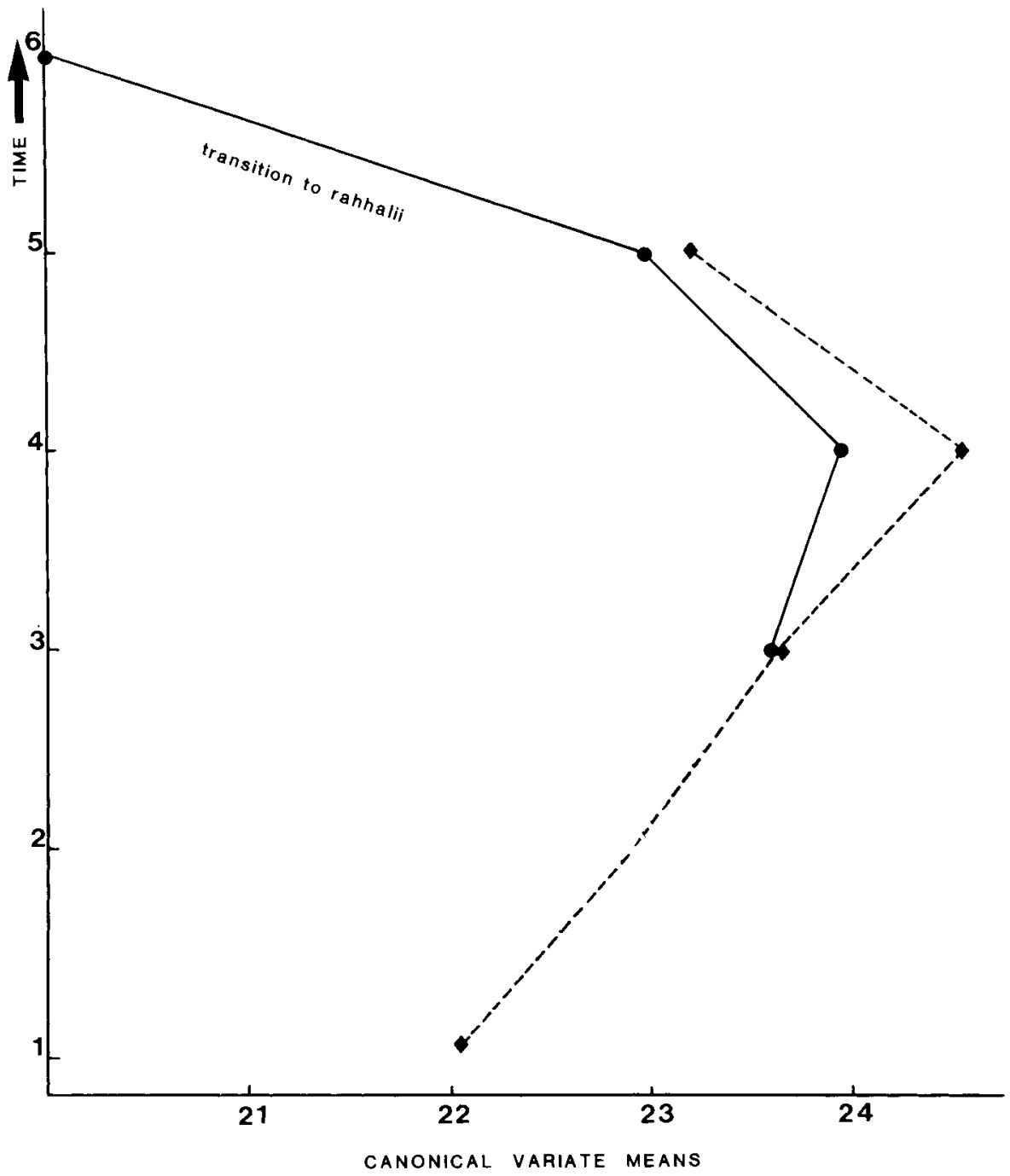

Fig. 1. First canonical variate means for the sequences in boreholes $\$ 09$ and \$21 plotted against stratigraphical position (the time axis is not drawn to scale). The sequence of borehole S21 is marked by dots and that of borehole S09 by diamonds. The zone of transition between the two species is denoted.

The selection differentials (Lande, 1979a) are listed in Table 3. These gradients are similar, though not identical (the angle between them is $15^{\circ} 30^{\prime}$ ) as is only to be expected, as the one carries through to the speciation event, whereas the other stops short at the top of the range of $V$. rotunda. Again, the conclusion is that the selection differentials point towards regional stability in the phenotype.

\section{DISCUSSION}

The world-wide Cenomano-Turonian transgression could lie at the root of the speciation event recorded here. Biogeographically, the new species inhabited a much more restricted area than the ancestral form and its vertical range seems also to have been severely restricted. Lande (1979b, p. 238) and Emlen (1973, pp. 39-40) point out that an isolated deme would not survive very long; the inability of $V$, rahhalii to establish itself in multiple demes could have been the cause of its extinction.

Regarding the evolutionary mechanism underlying the transition from rotunda to rahhalii, the material available can do no more than provide a hint as to what might have occurred. The phenotype is regionally stable and therefore the morphological changes in $V$. rotunda preceding speciation must be of genetic origin (not just local ecophenotypic variations). It is also shown that the morphological changes could have been caused by random genetic drift in demes of normal size for ostracods, in the absence of selection. It is 
Table 2. Summary of principal component analyses for samples from both boreholes.

\begin{tabular}{llllll}
\hline $\begin{array}{l}\text { Principal } \\
\text { component }\end{array}$ & Sample details & Var 1 & Var 2 & Var 3 & Var 4 \\
\hline first & $\begin{array}{l}\text { all levels of S21 } \\
\text { (incl. } O \text {. rahhalii) }\end{array}$ & 0.6 & 0.5 & 0.4 & 0.5 \\
& S09:148 to S09:154 & 0.6 & 0.5 & 0.4 & 0.6 \\
\multirow{4}{*}{ second } & All levels of S21 & $0.2-0.4$ & $-0.1-0.3$ & --0.9 & 0.3 \\
\multirow{4}{*}{ third } & S09:148 to S09:154 & $0.1-0.2$ & $-0.2-0.4$ & -0.9 & 0.3 \\
\multirow{3}{*}{ fourth } & All levels of S21 & unstable & -0.8 & 0.2 & $0.6-0.8$ \\
& S09:148 to S09:154 & $0.0-0.3$ & -0.8 & unstable & $0.4-0.7$ \\
& All levels of S21 & 0.7 & $-0.1-0.4$ & $-0.2-0.2$ & $-0.6--0.7$ \\
& S09:148 to S09:154 & 0.7 & $-0.1--0.4$ & -0.1 & -0.7 \\
\hline
\end{tabular}

Table 3. Selection differentials for the sequences of the two boreholes.

\begin{tabular}{lllll}
\hline Borehole & Var 1 & Var 2 & Var 3 & Var 4 \\
\hline S21 & 1.12 & 0.26 & 0.32 & 1.00 \\
S09 & 0.78 & 0.50 & 0.36 & 1.00 \\
\hline
\end{tabular}

likewise possible that the changes in morphology could have been brought about by fairly weak selection (cf. Lande, 1980a). Favouring this interpretation is the evidence of regional trend in the means.

It is not possible to decide in favour of one or other of these mechanisms. However, a fundamental evolutive force in the theories of Wright (1968), Simpson (1953) and Eldredge \& Gould (1972) concerns random genetic drift from one adaptive zone to another by the interaction of selection and genetic drift. Lande (1976, p. 324) has shown that the amount of exploration of the adaptive landscape is reduced exponentially in proportion to twice the effective population size and that during the evolution of many animal taxa, effective deme-sizes have been in the range of a few tens to a few hundreds of individuals (Lande, 1979b, p. 247). A very small amount of stabilizing selection can greatly increase the time taken to explore the adaptive zone by random genetic drift and so to cross any threshold into another adaptive zone which might exist. The computed population sizes for the rotunda-rahhalit transition are not incompatible with theoretical considerations for the time taken for speciation.

It is not yet possible to elucidate the full significance of the strongly reticulated morph of $V$. rotunda, although further work along the lines of that of Okada (1981) may turn out to be useful for studying evolutionary changes in reticulated ostracods. The increase in the number of polygons in connection with speciation may be due to epidermal cell divisions (observe the anteromarginal reticulations in the specimens illustrated on Pl. 1, figs. 1, 2, 3 compared with figs. 4, 5, 6; fig. 4 shows the already developed subdivided polygons in the proximal anteromarginal row). It would seem that the evolutionary mechanism suggested by Clark (1976) whereby speciation can occur by environmentally triggered polymorphism, merits consideration, rather than chromosomal rearrangements, as the effects of such, even in Drosophila, do not affect the morphological characteristics usually used by taxonomists (Spieth \& Heed, 1972). In general, autosomal rearrangements which preserve the genetic content of the chromosomes usually do not cause noticeable phenotypic modifications, other than reducing heterozygotic fertility (Lande, 1979b, p. 236).

\section{ACKNOWLEDGEMENTS}

I wish to thank the Director of the Service Géologique du Maroc for the material used in this study and Dr. Idriss Rahhali of the same organization for guiding me in the field and for placing his cxpert knowledge of the geology of the Tarfayan Basin at my disposal. Mrs. Eva Reyment took the SEM photographs and measured the specimens. The work was partly supported by grant G2320-110 of the Swedish Natural Science Research Council. 


\section{REFERENCES}

Bulmer, M.G. 1980. The Mathematical Theory of Quantitative Genetics. x +256 pp., Oxford University Press, Oxford.

Campbell, N.A. \& Reyment, R.A. 1978. Discriminant analysis of a Cretaceous foraminifer using shrunken estimators. Math. Geol., New York, 10, 347-359.

Clark, W.C. 1976. The environment and the genotype in polymorphism. Zool. J. Linn. Soc., London, 58, $255-262$.

Eldredge N. \& Gould, S.J. 1972. Punctuated equilibria: an alternative to phyletic gradualism. In $\mathrm{T}$. Schopf (Ed.), Models in Paleobiology, pp. 82-115, Freeman, Cooper \& Co., San Francisco.

Emlen, J.M. 1973. Ecology: an Evolutionary Approach. Addison-Wesley, Reading, Mass., $493 \mathrm{pp}$.

Falconer, D.S. 1960. Introduction to Quantitative Genetics. Oliver \&. Boyd, Edinburgh. 365 pp.

Hallauer, A.R. \& Miranda, J.B. 1981. Quantitative Genetics in Maize Breeding. XII +468 pp. lowa State Press, Iowa.

Hartl, D.L. 1980. Principles of Population Genetics. xvi +488 pp. Sinauer Associates Inc., Mass.

Kempthorne, O. 1957. An Introduction to Genetic Statistics. Wiley \& Sons, New York.

Lande, R. 1976. Natural selection and random genetic drift in phenotypic evolution. Evolution, Chicago, 30, 314-334.

Lande, R. 1979a. Quantitative genetic analysis of multivariate evolution, applied to brain:body size allometry. Evolution, Chicago, 33, 402-416.

Lande, R. 1979b. Effective deme sizes during longterm evolution estimated from rates of chromosomal rearrangement. Evolution, Chicago, 33, 234-251.

Lande, R. 1980a. Microevolution in relation to macroevolution. Paleobiology, Chicago, 6, 233-238.

Lande, R. 1980b. Genetic variation and phenotypic evolution during allopatric speciation. Am. Nat., Chicago, 116, 463-479.

Okada, Y. 1981. Development of cell arrangement in ostracod carapaces. Paleobiology, Chicago, 7, $276-280$.
Raup, D.M. 1977. Stochastic models in evolutionary palaeontology. In Hallam, A. (Ed.), Patterns of Evolution, as Illustrated by the Fossil Record. Developments in Palaeontology and Stratigraphy, 5, 59-78. Amsterdam.

Reyment, R.A. 1978. Quantitative biostratigraphical analysis exemplified by Moroccan Cretaceous ostracods. Micropaleontology, New York, 24, 24-43, 2 pls.

Simpson, G.G. 1953. The Major Features of Evolution. 434 pp., Columbia University Press, New York.

Spieth, H.T. \& Heed, W.B. 1972. Experimental systematics and ecology of Drosophila. A. Rev. Ecol. Syst., Palo Alto, California, 3, 269-288.

Strickberger, M.W. 1976. Genetics, 2nd Edition, Macmillan, New York.

Theisen, B.F. 1966. The life history of seven species of ostracods from a Danish brackish-water locality. Meddr. Danm. Fisk. og Havunders., Copenhagen, N.S., 4(8), 215-270.

Uffenorde, H. 1972. Ökologie und jahreszeitliche Verteilung rezenter benthonischer Ostracoden des Limski-Kanal be Rovinj (nördliche Adria). Göttinger Arbeiten zur Geologie und Paläontologie, Göttingen, 13, $121 \mathrm{pp}$.

Wiedmann, J., Butt, A. \& Einsele, G. 1978. Vergleich von marokkanischen Kreide-Küstenaufschlüssen und Tiefseebohrungen (DSDP): Stratigraphie, Paläoenvironment und Subsidenz an einem passivem Kontinentalrand. Geol. Rdsch., Stuttgart, 67, 454-508.

Wright, S. 1931. Evolution in Mendelian populations. Genetics, Princeton, 16, 97-159.

Wright, S. 1932. The roles of mutation, inbreeding, crossbreeding, and selection in evolution. Proceedings VI International Congress on Genetics, 1, 356-366.

Wright, S. 1968. Evolution and the Genetics of Populations, 1, Genetic and Biometric Foundations, vii +469 pp., University of Chicago Press, Chicago. 